\title{
A RFID based Inventory Control System for Nigerian Supermarkets
}

\author{
Olutayo Boyinbode \\ Department of Computer Science, \\ Federal University of Technology, Akure
}

\author{
Olufemi Akinyede \\ Department of Computer Science, \\ Federal University of Technology, Akure
}

\begin{abstract}
Having to spend 20 to 30 minutes on a queue, waiting for bought items to be scanned is a common problem that brings concern in this current shopping day in developing countries of Africa. This does not only cause wastage of time for the customers but also, it's a sure sign which shows the incompetence of the performance of current barcodes checkout technology. To resolve this problem, a new technology is introduced which can improve the inventory system process. This technology has great potential for the automation of inventory control system which uses the $13.56 \mathrm{MHz}$ operating frequency RFID technology. This paper describes and implements a RFID based inventory control system for supermarkets in Nigeria.
\end{abstract}

\section{General Terms}

RFID Technologies, RFID Based Inventory Control System.

\section{Keywords}

RFID Readers, RFID Tag, Barcodes, Stocks, Inventory control system

\section{INTRODUCTION}

A Radio Frequency Identification (RFID) system is a form of recognition system which makes use of radio waves in retrieving data from an appliance called a tag or transponder. There are many applications of RFID in various areas in our everyday lives such as in bookstores, libraries, asset tracking, traffic management, supply chain etc. RFID offers a fast and effective way of collecting information, for instance, tracking stock in a warehouse, as well as tracking the whereabouts of items [2, 3, 4]. RFID based stock and inventory system is an electronic and real-time system. This system uses radio frequency for data networking medium to communicate between control centre and the products. The products or items will be equipped with RFID tag which will store current data and information about the stock. This system operates in real-time, each products or items stored are being monitored and the data will be displayed on the control centre computer. This happens as a result of the transmitted signal to the RFID tags by the RFID reader. Once the RFID tag detects the signals that are transmitted, data will be sent to the RFID reader. The RFID tags are scanned by the RFID reader and the control computer centre then show the information and status which has been obtained from each tag [1]. Though as an automated system the implementation of RFID technologies has been introduced long ago, it has not been widely employed in the retail sector. Most retailers especially in developing countries of Africa have no idea that an RFID inventory system holds a great promise in the retailer world for both the customer and also the retailer itself. This has brought the motivation for designing and implementation of a low cost and high accuracy RFID-based inventory system.

\section{RFID AND BARCODES TECHNOLOGIES}

Barcode is an optical machine readable representation of data which relates to the object to which it is attached. Initially barcodes systematically represented data by varying the widths and spacing of parallel lines, and may be referred to as linear or one dimensional. Later they evolved into rectangles, dots, hexagons and other geometric pattern in two dimensions. Barcodes are usually scanned by special optical scanners called barcode reader. Barcodes are used to automate supermarket checkout systems, and also now used in automatic identification and data capture (AIDC). Most Supermarkets in Nigeria still operate with the barcode technology.

Radio Frequency Identification (RFID) is a general term for technologies which identifies people or object in an automatic manner via radio waves.

RFID is a small electronic device that comprises of an antenna and a small chip. This RFID provides unique identification of an object. In order to retrieve identifying information the RFID device must be scanned.

RFID uses a method that remotely retrieves data using a device called RFID Tag or Transponders. This RFID tag can be embedded on a product or attached to a person or an animal. An RFID system is made up of some components, the tag readers, tags, edge server, application software and middleware. When an RFID tag passes through an electromagnetic zone, the reader's activation signal is detected, then the data encoded in the tag's integrated circuit (silicon chip) is decoded and the data is been transferred to the host computer for processing. In some of the RFID solutions, return receipt is generated.

RFID is based on two types of technology used in the management of inventory movement; these are passive and active technology. The active RFID technology makes use of fixed tags which are assigned all through a store such that each time a product having a RFID tag attached to it passes the reader, the inventory management software records the movement of the product. Active system works best in environment where real time security problems exist or tracking of inventory in real-time. Passive RFID technology requires the use of handheld readers to monitor inventory movement. The accuracy of moving stock around a store is greatly increased due to the fact that RFID has a reading range of up to 40 feet using passive technology and 300 feet using active technology. 


\subsection{Advantages of RFID over Barcode}

Comparing barcode inventory control systems with RFID technology, there are noteworthy advantages, which include [5];

- Line of sight access not required to be read. This makes it possible to read from afar even in an enclosed bag or box.

- If tag is removed from correct location it can trigger security alarm system.

- RFID tag and RFID reader or scanners are not so orientation sensitive.

- Without the intervention of an operator with the RFID, data logging and automatic scanning is possible, but for barcode the scanning has to be done deliberately by a person with a scanner

- Each tag can hold more than just a unique product code because of its read/write capabilities and this makes each item known as an individual instead of just recognising a product type.

- Items can be labelled individually.

- With the right technology more than one tag can be concurrently read.

- RFID can be read only or read-write.

- The level of integrity is very high. (Check sum character encoding).

- It is easier to counterfeit a barcode, but RFID tag cannot be counterfeited.

- A tag is more difficult to counterfeit than a barcode. Hence it provides a high degree of security and product authentication. The supporting data infrastructure can allow data retrieval and product tracking anywhere provided the scanner/reader is close enough to the tag.

- It can be used in hostile environment since the technology is rugged, cannot be affected by moisture or dust.

The technology can be easily updated.

- The technology could be adapted to a range of circumstances for instance a chip this can be inserted within a suit or dress, so when the dress is sent to the cleaner or washing machine, the right cleaning procedure can be gotten automatically and applied.

\section{HOW RFID BASED INVENTORY CONTROL SYSTEM WORKS}

The RFID tag informs the RFID reader which item is being purchased by the customer. Information is transmitted from the reader to the computer by sensing the tag, reading it and information read is sent to the software. The number from the tag is interpreted by the software and matches it with the numbers of the type of commodities or products they represent. The software is a computer based system for tracking sales, product level, orders, bill of material and deliveries. This helps the store owner to keep track of sales and inventory keeping the store updated of which items are selling.
Specialized software is used in keeping track of how much stock is going out via purchase and how much remains on shelves and in the store, giving managers real time picture of what is happening. The software analyses the data and keeps record of information. In business that handles transactions revolving around consumer goods, it is important to ensure quality control with a proper control system, a large retail store sometimes may run out of stock of important item. A good inventory control system will alert the retailer when it is time to re-order [5, 6]. Most supermarkets in Nigeria still operate with barcode technology, but with the numerous advantages of RFID technologies clearly explained in section 2.1 , there is need for supermarkets in Nigeria to embrace RFID technologies. Our case study is NAO supermarket, one of the biggest supermarkets in Akure, Nigeria.

The major primary source of gathering information involved an oral interview which was carried out at NAO supermarket Akure, Nigeria, in a bid to get more understanding about how their inventory control system works and the challenges and limitations with the barcode system currently being used.

NAO supermarket has the following problems and limitations with barcode system.

- Barcode can be affected by dust thereby hindering the scanner from reading it.

- $\quad$ Since barcode are in general paper labels, or printed on paper based packaging (although not always), they can easily be damaged.

- Barcode cannot be printed on all kinds of items.

- Limited information can be stored using Barcodes i.e. Barcodes cannot store the calories content of a product, so will not be able to warn a consumer about the calories intake of that particular product.

- Barcodes are slower in speed than RFID Customers were on a queue at NAO supermarkets and also the customers' goods have to be manually checked on their way out to detect stolen items. See Figure 1 and 2 below.

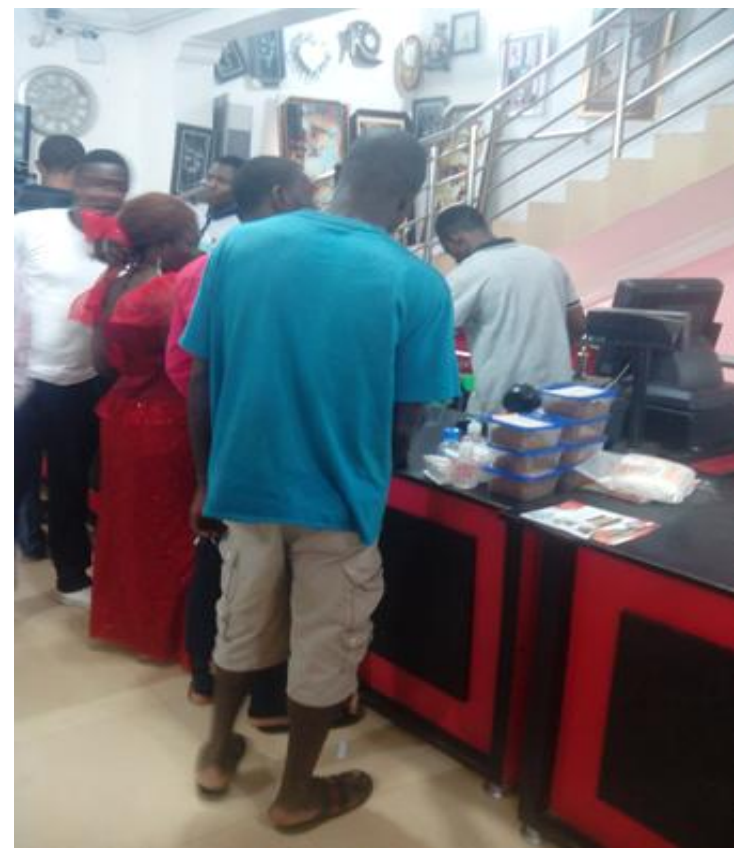




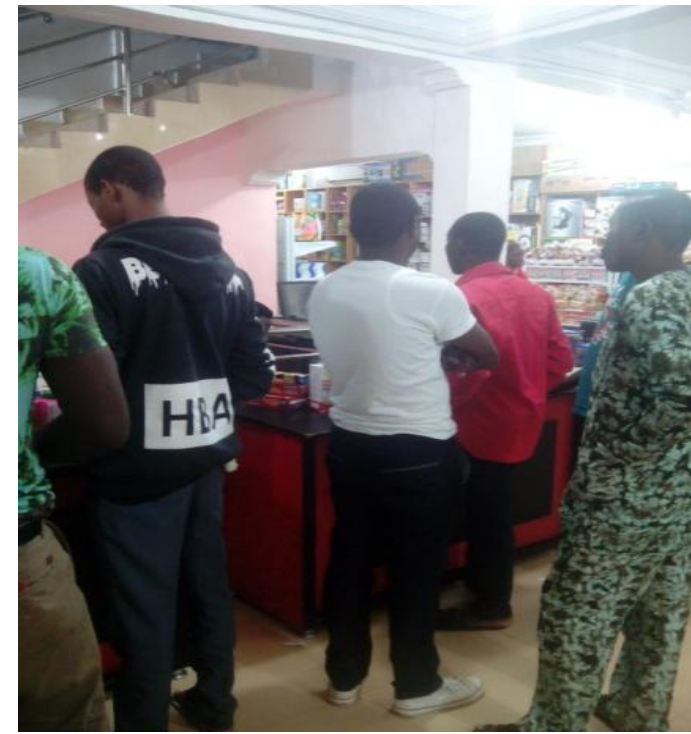

Fig 1: Customer waiting to be attended to at NAO Supermarket

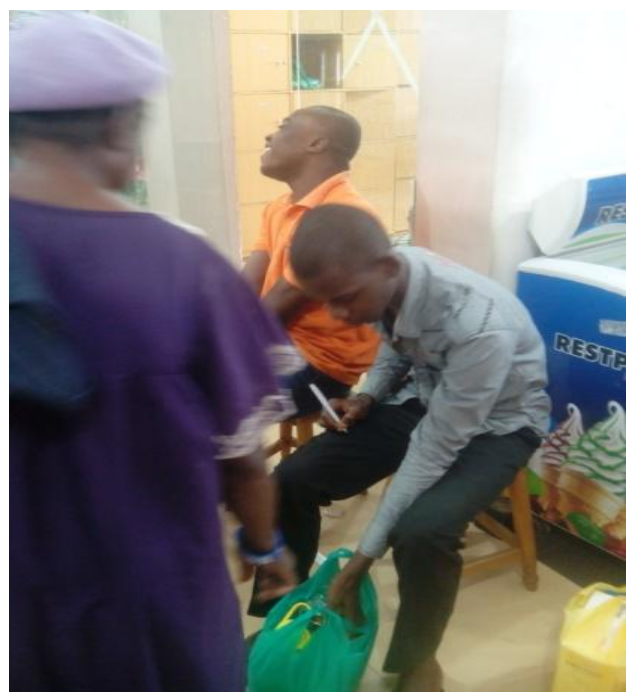

Fig 2: Manually checking the goods before the customer goes out at NAO Supermarket

RFID technology overcomes the limitations of barcodes. When RFID technology becomes as ubiquitous as barcodes in

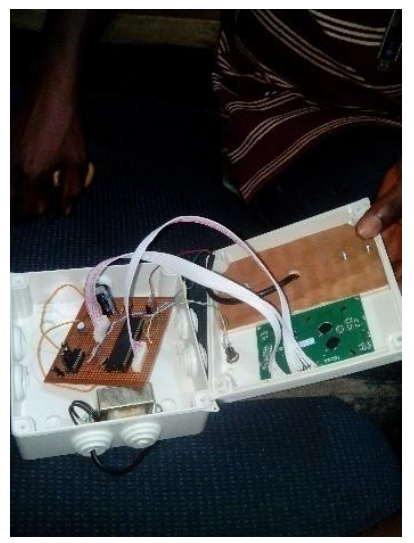

Fig 3: The hardware component under construction the distribution chain, then the unit cost of the 'tag' will be considerably cheap as the printed barcodes. Because of the more advantages that RFID tag has, especially the security features, they have become the preferred inventory system for consumer durables, and high value capital goods [5].

\section{DESIGN}

The RFID Inventory Control system is equipped with a RFID reader that is capable of effectively detecting and capturing response signals transmitted from the RFID tags attached on each item that passes through the scanning zone.

Then the tag response passes into the reader module in order to identify the tag unique code and goes through the microcontroller for further data processing. The main data processor of this system is the microcontroller. It is programmed using Assembly language. The microcontroller can function as a computer with or without addition of external digital parts.

All instruction signal and logic signal pass into the microcontroller for action determination. In addition, a LED indicates the status of the system power indicator, Radio Frequency on/off indicator. The LCD screen which is an electronic display module is connected to the microcontroller; this enables the information about the products that is read from the RFID tag by the RFID reader to be displayed.

\section{IMPLEMENTATION}

The system design which consist of the RFID reader which interacts with the RFID tags, microcontroller, written in assembly program which helps in the comparing of information gotten from the tags by the reader with what has been stored in the database. A LCD screen is used to display the information read to the customer. Based on this result, the system's main function is to display beneficial information about the tagged product. The system can function well when it detects a tag. In this work, the RFID based inventory system is designed to give customers detailed information about product purchased automatically. The system consists of microcontroller programmed in assembly code, relay circuit, power supply unit circuit and LCD display screen as shown in figure 3, 4and 5 . When the system is connected to a power supply, a default message is displayed, and it waits to detect a tag, once the tag is detected, it displays the information contained in the tag. Waits few seconds after displaying the information, then returns back to default message, this process is repeated for every tag detected.

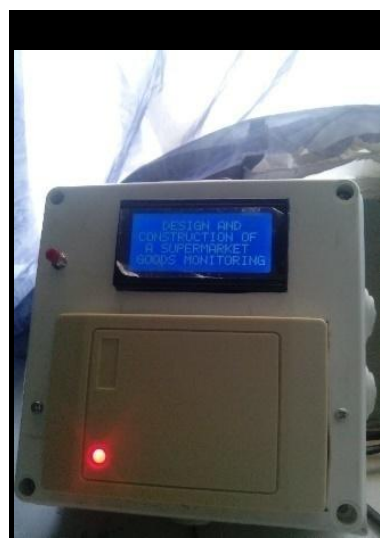

Fig 4: The working system 

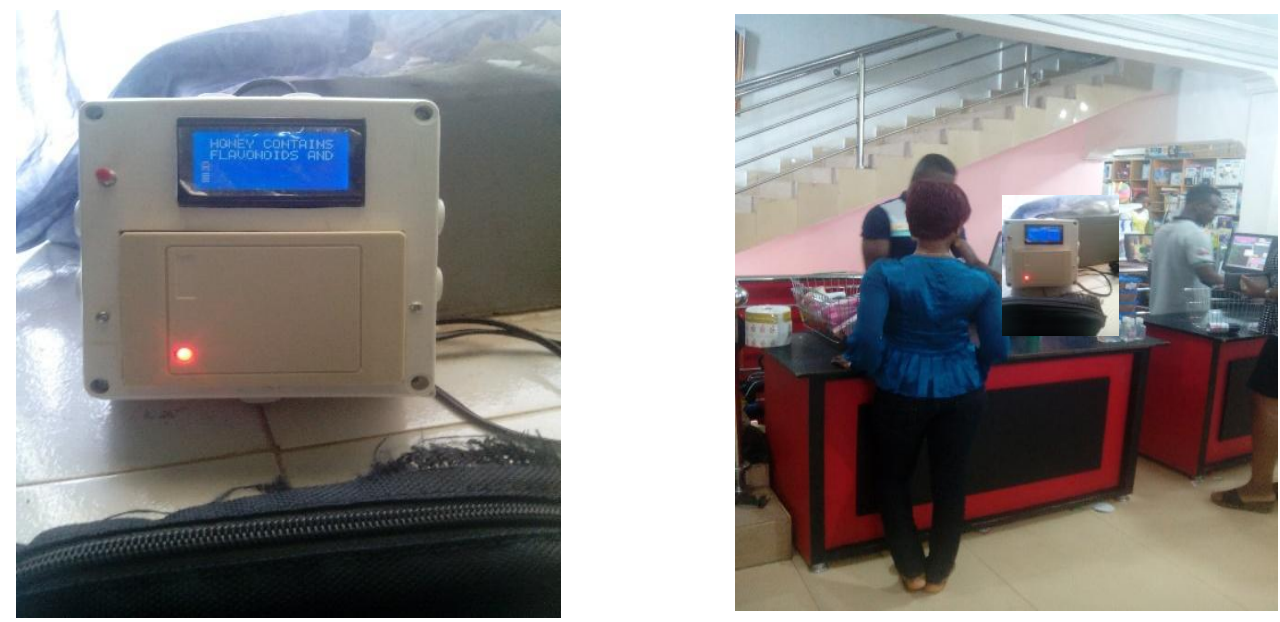

Fig 5: System reading information from tagged item at NAO Supermarket

In this work, one of the major advantages of using RFID over barcode is that RFID is used to store information about a product that is beneficial to the customer, which is limited in barcode. In case of food items it displays the calories, so that the consumers know what they are consuming. Below are the list of products used and the information the RFID reader displays about these product to the customer.

1. Snicker chocolate: Manufactured by Mars Nederland, produced August 2014, expires August 2015 , price-N1600 calorie content in $100 \mathrm{~g}-484 \mathrm{kcal}$, contains peanut, this can add $1 \mathrm{~kg}$ to your body weight. See figure 6 .

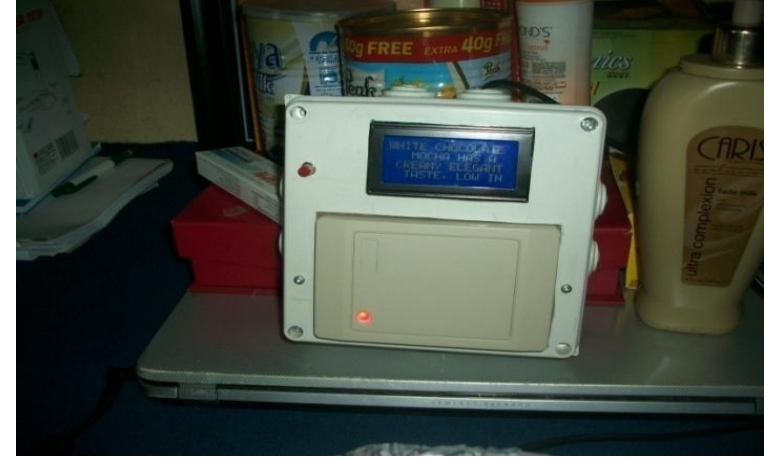

Fig 6: Snicker Chocolate in RFID Display

2. Linea Anna jacket: produced by prada, price$\mathrm{N} 20,000,73 \%$ polyester, wash with warm water, best worn in cool weather. See figure 7
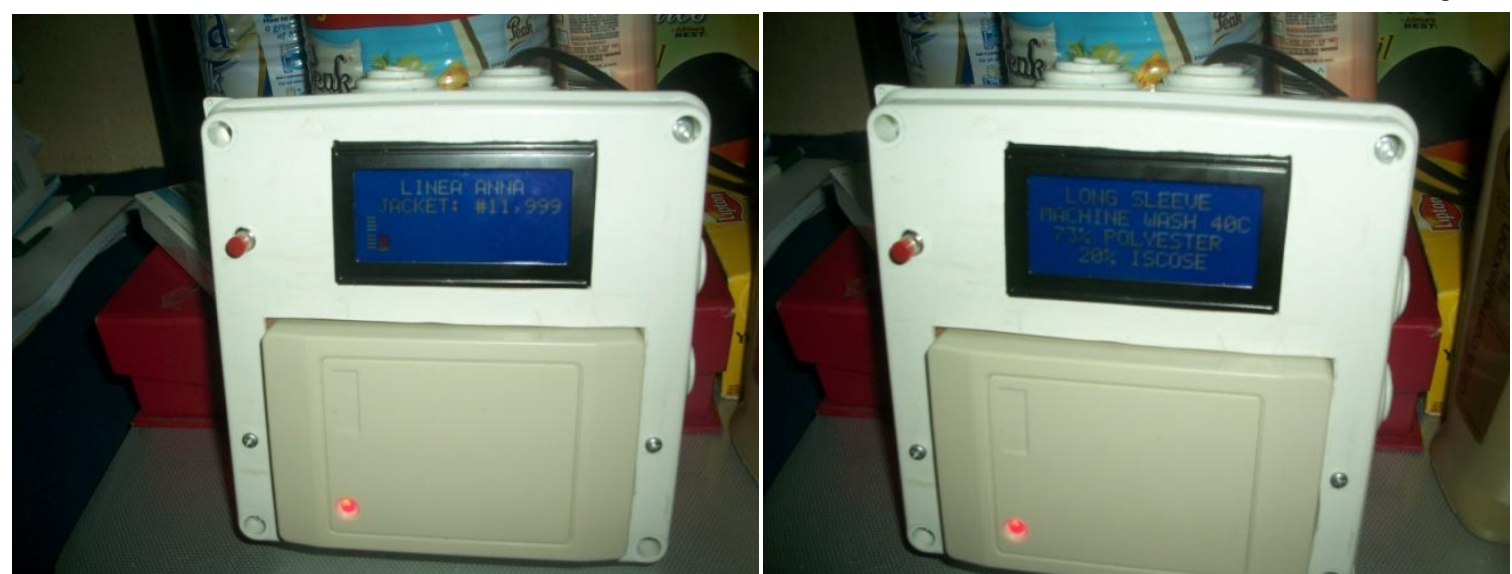

Fig 7: Linea Anna jacket in RFID Display

3. Sunshine honey: produced by Elisa companies, price N1100, its natural, a good substitute for sugar, very good for all age groups. See below. 


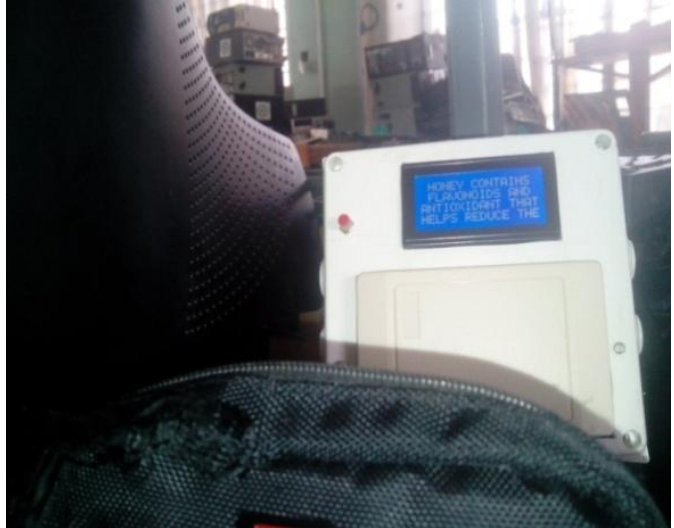

Fig 8: Sunshine honey in RFID Display

4. shoe: produced by Eva wears, price N4000, leather shoes, best worn during the dry season. See below.

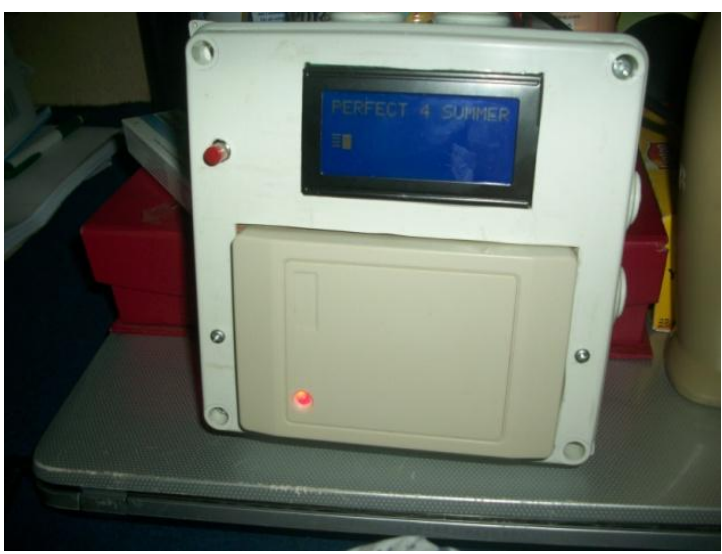

Fig 9: Eva Shoe in RFID Display

5. Caris cream: produced by Gianni Badu, price $\mathrm{N} 3000$, contains $2.0 \%$ hydroquinone, ultra complextion cream, product contains alpha hydroxy acid(AHA) that may increase skin sensitivity to sun which can lead to sunburn. See below.

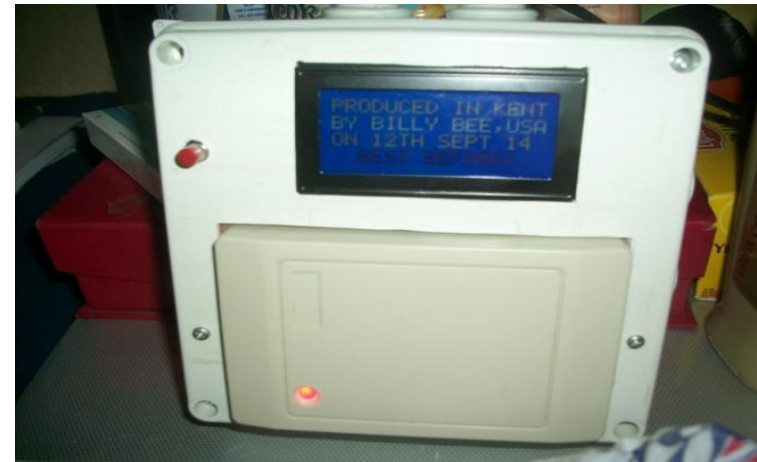

Fig 10: Caris Cream in RFID Display

6. NAPA mik: produced by NAPA, low cholesterol, dillute with warm water before consumption. See below.

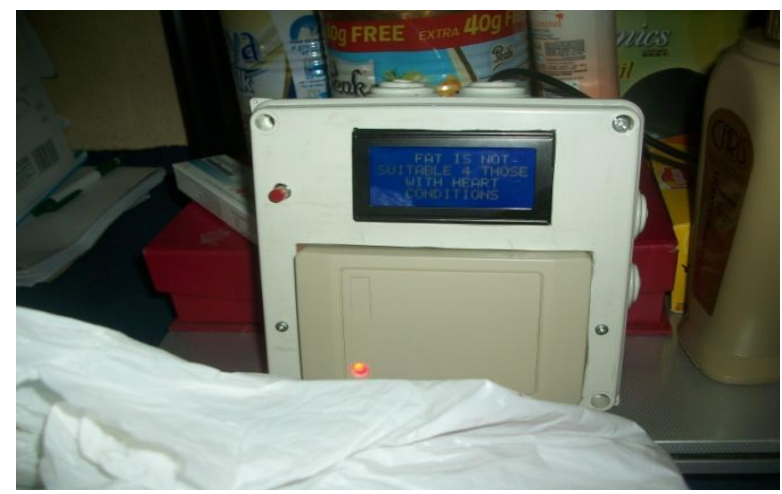

Fig 11: NAPA milk in RFID Display

\section{RFID-BASED INVENTORY CONTROL SYSTEM}

The graphical user interface (GUI) of RFID Based Supermarket comprises of checkout product information and the total price displayer. The check-out product information displayer shows information such as product ID, Tag ID, product name, and product price of the checkout item scanned by the reader.

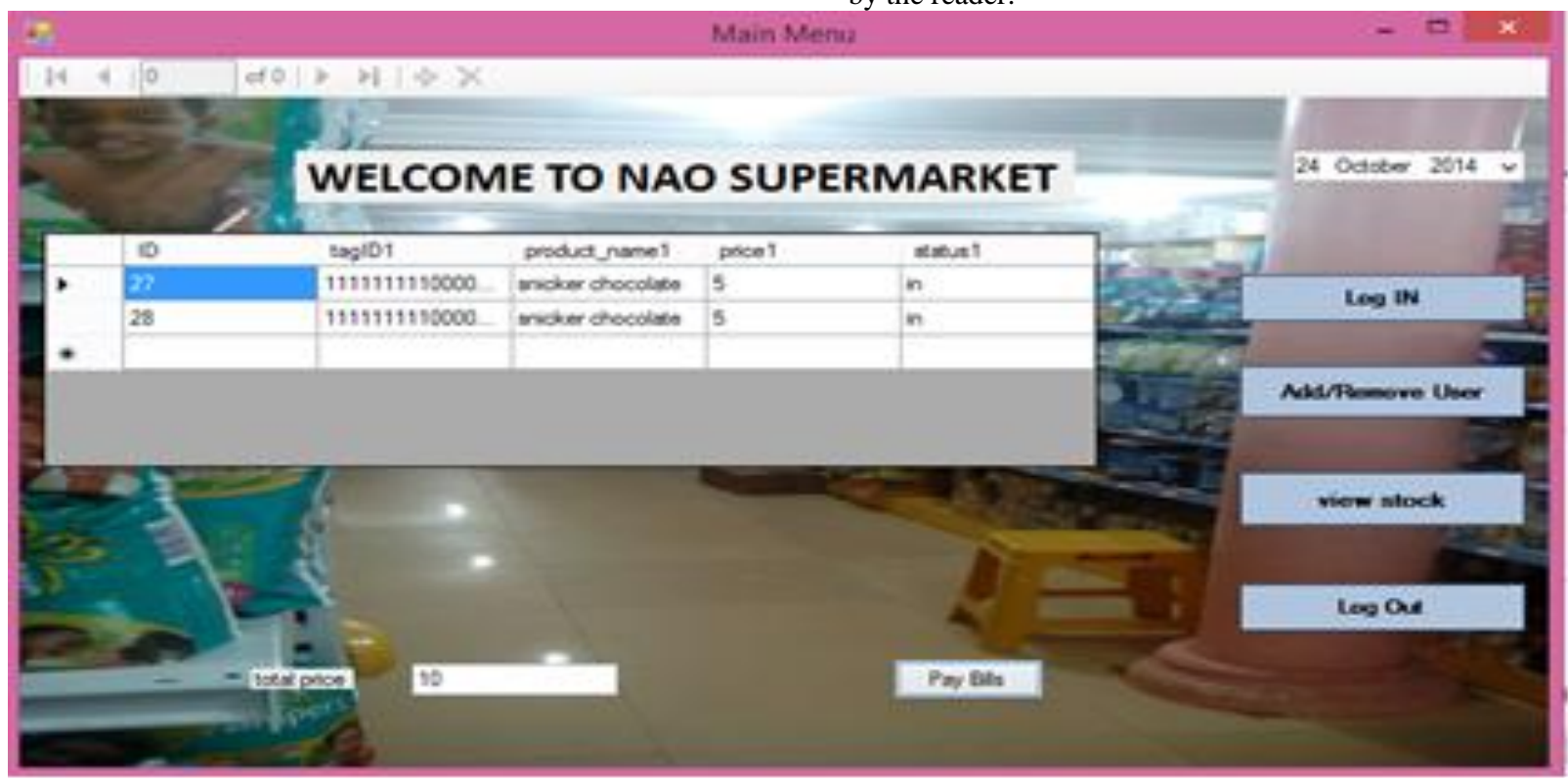

Fig 12: GUI main menu 


\subsection{Administrator Lock Function}

This is implemented to the GUI program so as to disable some function of the program that should not be accessed by normal user, and to also prevent normal user from changing the settings of the graphical user interface.

\subsection{Add/Remove Access user Function}

The function of this is to withdraw or insert any access user to the system data base.

\subsection{Pay bill function and remove item function}

The pay bill function is incorporated in order to enable the user to checkout their purchased item. Once the button is clicked, the graphical user interface program displays the total amount of goods purchased.

\subsection{View stock function}

The function of the view stock is to enable the admin user to easily access the database and check for the quantity of available stock and also the status of goods whether they are in or out.

\subsection{Adding stock to database}

This interface enables addition of information to the database via the interface, once a tag is detected, and information about the product is added and then the "add stock" button is clicked; this enters the information into the database. The buttons for connecting and disconnecting to and from the $\mathrm{COM}$ port are the; connect and disconnect buttons respectively (See figure 13).

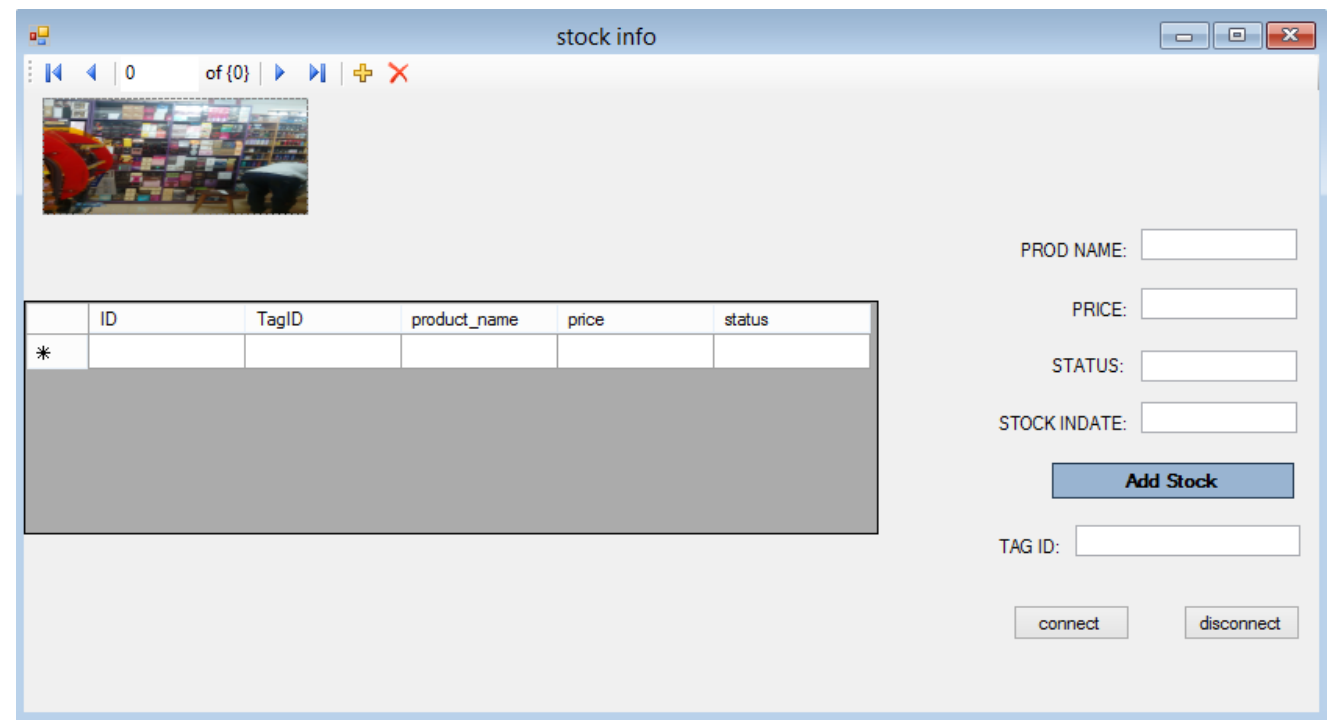

Fig 13: Adding stock to database

\section{CONCLUSION}

The RFID based inventory control system was successfully designed and implemented in NAO Supermarket Akure, Nigeria. This system is capable of reading and interpreting correct information transmitted from the RFID tag attached to items. The RFID reader reads the tag, and the data is compared in the microcontroller to match the built in data for status display which is indicated with an LCD display. The customer gets to see some beneficial information about the products being purchased which can go a long way in improving the life of a consumer i.e. being able to get a detailed knowledge about the product they are consuming.

\section{REFERENCES}

[1] Azra Suzzana, W. (2008). Stock And Inventory Control System Using Radio Frequency Identification (RFID).

[2] Garfinkel, S. and Rosenberg, B. (2006), RFID Applications, Security, and Privacy, Addison-Wesley, Upper Saddle River
[3] Grover, P., \& Ahuja, A. (2010). Radio frequency identification based library management system. International Journal of Advanced Computer Science and Applications, 1, 41-45.

[4] Hamilton, D., Michael, K. and Wamba, S.F. (2009), "Using RFID to overcome inventory control challenges: a proof of concept", Proceedings of The Sixth International Conference on Ubiquitous Intelligence and Computing (UIC-09), Brisbane, Australia, July, pp. 353 366.

[5] Michael, K., \& McCathie, L. (2005, July). The pros and cons of RFID in supply chain management. In Mobile Business, 2005. ICMB 2005. International Conference on (pp. 623-629). IEEE.

[6] Ting, S. L., \& Tsang, A. H. (2012). Design of an RFIDbased inventory control and management system: a case study. The West Indian journal of engineering Vol.34, Nos.1/2, January 2012, pp.70-79. 